\title{
Early evolutionary diversification of mandible morphology in the New World monkeys (Primate, Platyrrhini)
}

\author{
Guido Rocatti a , Leandro Aristide a , Alfred L. Rosenberger ${ }^{\mathrm{b}}$, S. Ivan Perez ${ }^{\mathrm{a},{ }^{*}}$ \\ a División Antropología, Facultad de Ciencias Naturales y Museo, Universidad Nacional de La Plata, CONICET. 122 y 60, 1900, La Plata, Argentina \\ ${ }^{\mathrm{b}}$ Department of Anthropology and Archaeology, Brooklyn College, CUNY, 2900 Bedford Ave., Brooklyn, NY, USA
}

\section{A R T I C L E I N F O}

Article history:

Received 24 August 2016

Accepted 3 August 2017

\section{Keywords:}

Paleontology

Neontology

Phenotypic evolution

Mandible

Fossils

Neotropical

\begin{abstract}
A B S T R A C T
New World monkeys (order Primates) are an example of a major mammalian evolutionary radiation in the Americas, with a contentious fossil record. There is evidence of an early platyrrhine occupation of this continent by the Eocene-Oligocene transition, evolving in isolation from the Old World primates from then on, and developing extensive morphological and size variation. Previous studies postulated that the platyrrhine clade arose as a local version of the Simpsonian ecospace model, with an early phase involving a rapid increase in morphological and ecological diversity driven by selection and ecological opportunity, followed by a diversification rate that slowed due to niche-filling. Under this model, variation in extant platyrrhines, in particular anatomical complexes, may resemble patterns seen among middle-late Miocene (10-14 Ma) platyrrhines as a result of evolutionary stasis. Here we examine the mandible in this regard, which may be informative about the dietary and phylogenetic history of the New World monkeys. Specifically, we test the hypothesis that the Simpsonian ecospace model applies to the platyrrhine mandible through a geometric morphometric analysis of digital images of the jaws of extant and extinct species, and we compare these results to those obtained using a phylogenetic comparative approach based on extant species. The results show a marked phylogenetic structure in the mandibular morphology of platyrrhines. Principal component analyses highlight the morphological diversity among modern forms, and reveal a similar range of variation for the clade when fossil specimens are included. Disparity-Through-Time analysis shows that most of the shape variation between platyrrhines originated early in their evolution (between 20 and $15 \mathrm{Ma}$ ). Our results converge with previous studies of body mass, cranial shape, the brain and the basicranium to show that platyrrhine evolution might have been shaped by an early increase in morphological variation followed by a decelerated rate of diversification and evolutionary stasis.
\end{abstract}

๑) 2017 Elsevier Ltd. All rights reserved.

\section{Introduction}

New World monkeys, or platyrrhines, are one of the main clades of the order Primates and an example of a major mammalian evolutionary radiation in the Americas. The clade is considered to be monophyletic and has a relatively long evolutionary history of nearly 30 million years (Ma) spanning South and Central America, and the Caribbean (e.g., Rosenberger et al., 2009; Perez et al., 2013; Opazo et al., 2006). The fossil record of platyrrhines is contentious, but there is well supported paleontological evidence of their presence in the late Oligocene (ca. 26 Ma; Fleagle and Tejedor,

\footnotetext{
* Corresponding author.

E-mail addresses: iperez@fcnym.unlp.edu.ar, ivanperezmorea@gmail.com (S.I. Perez).
}

2002) or even in the late Eocene (>35 Ma; Bond et al., 2015). Therefore, the clade's earliest representatives probably invaded the continent by the Eocene-Oligocene transition, 35 Ma, and evolved in isolation from the Old World primates from then on (e.g., Rosenberger, 2002; Tejedor and Rosenberger, 2008; Fleagle, 2013; Perez et al., 2013). While taxonomic interpretations differ, a picture of their diversity depicts a radiation within the Americas that evolved into several lineages that comprise approximately 125 extant species in 16 or 17 genera and five main clades (i.e., families or subfamilies; Wilson and Reeder, 2005; Perelman et al., 2011; Aristide et al., 2015a).

Together with the large species diversity, platyrrhines have occupied a wide range of ecological niches, showing considerable diversity in many ecologically interpretable traits (e.g., Terborgh, 1983; Kinzey, 1997; Fleagle, 2013). Particularly, the clade presents 
large variety in: a) diet composition, including different proportions of exudates, fruit pulp, seeds, leaves, and insects; b) diet quality, from low quality diets based mainly on leaves to higher quality diets based on protein-rich insects and seeds; c) social group size and organization, varying in group size from 2 to 200 individuals; and d) mating patterns, with monogamous, polyandrous, and polygynous systems. Moreover, they evolved a diversity of body sizes (with species ranging from $\sim 100 \mathrm{~g}$ to $\sim 10 \mathrm{~kg}$ [e.g., Hershkovitz, 1977; Ford and Davis, 1992; Rosenberger, 1992; Fleagle, 2013; Aristide et al., 2015a]), body shapes (Youlatos and Meldrum, 2011), dental morphologies (Rosenberger, 1992; Winchester et al., 2014) and cranial morphologies (Perez et al., 2011; Aristide et al., 2015b).

Previous studies have suggested that the marked morphological and ecological diversity of platyrrhines originated relatively early in the evolutionary history of the group, during the initial branching processes corresponding with the time of the origin of the main extant clades (see Delson and Rosenberger, 1984; Rosenberger, 1979, 1980, 1992, 2002). Specifically, these studies have postulated a local version of the Simpsonian ecospace model (Simpson, 1944; Benton, 2015; see Aristide et al., 2015a), where an early phase of rapid increase in morphological and ecological diversity - correlating with a high rate of evolutionary innovation - is driven by powerful selection and ecological niche opportunity (Losos and Mahler, 2010). In Simpson's model, after the initial phase, the rate of evolutionary diversification slows down as niches are filled. Some taxa may become extinct while new species may emerge within clades, mainly by subdividing niches already pioneered by the ancestral species. It has also been proposed that the anatomical and adaptive character of the extant platyrrhine genera and species may resemble the morphological and ecological variation seen in Miocene fossil forms due to long periods of relative evolutionary stasis (Rosenberger, 1979, 1992; Rosenberger et al., 2009; Aristide et al., 2015a).

Here, we analyze the mandible to test the above proposals. Rosenberger $(1980,1992)$ suggested that during the initial differentiation of platyrrhines, two fundamental patterns of jaw morphology arose (Fig. 1). As now seen among the extant forms, in the cebid clade (excluding Aotus, a genus now often classified as a cebid but then considered what modern classifications call a pitheciid), the lower border of the corpus is approximately horizontal, paralleling the occlusal plane, and the angular region forms a right angle (Fig. 1b). In atelids and pitheciids, and specifically in Aotus, the profile is different. The jaw deepens posteriorly and tends to become wider in the anteroposterior direction in the region of the mandibular angle (Fig. 1a). In extreme variations, as in pitheciids such as Callicebus (and occasionally Aotus), and in the atelid Alouatta, the mandible is greatly deepened below the molars and the gonial region is widened in depth and anteroposterior length.
These two patterns may be the ancestral conditions of the major clades (Rosenberger, 1980, 1992), as they predominate among the genera included in these clades. However, there are also exceptions in both mandibular morphologies that appear to converge on the alternative condition. For example, the cebid Leontopithecus presents a jaw profile that tends to deepen posteriorly, while Chiropotes and Cacajao tend to display the opposite silhouette; Aotus, if considered to be a cebid, would also be an example, having a more pitheciid-like morphology. There are alternative explanations for the evolution of patterns of mandibular morphology in platyrrhines. It is well established that the lower jaw is biomechanically and adaptively important, and presumed to reflect diet to certain degree (e.g., Hylander, 1979, 1985; Anapol and Lee, 1994; Ravosa, 1996; Ross et al., 2012; Meloro et al., 2015). Specifically for platyrrhines, Rosenberger $(1980,1992)$ pointed out the correspondence between mandible morphology and diet. The extant cebids have frugivorous and insectivorous feeding habits and have a lightweight feeding mechanism, while atelids have frugivorousfolivorous habits and show a heavy-duty masticatory system (Rosenberger, 1980). This suggests that the evolutionary pattern of the mandible does not correspond with a neutral (Brownian motion) expectation. Alternatively, previous work based largely on the living species pointed out that patterns of mandibular morphology track the phylogenetic history of platyrrhines (e.g., Rosenberger, 1977, 1992; Meloro et al., 2015; Terhune et al., 2015), suggesting that its diversification might not depend mainly on diet or biomechanical factors. This suggests that platyrrhine mandible evolution was a deeply complex process.

In particular, the timing and mode of evolution of such platyrrhine mandible morphological patterns are far from being understood, and the fossil record is the only direct source of evidence to explore them. For platyrrhines, the record remains relatively small but is nonetheless informative. The earliest platyrrhine fossils date to the late Eocene (Perupithecus ucayaliensis, found recently at Santa Rosa, Peru; Bond et al., 2015) and late Oligocene (Branisella boliviana and Szalatavus attricuspis, both found at Salla, Bolivia; Wolff, 1984; Rosenberger et al., 1991; Fleagle, 2013). The phylogeny of these fossils is not well determined. Moreover, the Patagonian region of Argentina and Chile has produced several platyrrhine fossils from early and middle Miocene deposits (e.g., Chilecebus carrascoensis, Dolichocebus gaimanensis and Tremacebus harringtoni, from the early Miocene; Soriacebus ameghinorum, Carlocebus intermedius and Homunculus patagonicus, from the middle Miocene). Here, too, while these taxa are undisputedly platyrrhine, their phyletic interrelationships are under debate (e.g., Kay, 1990; Kay et al., 2008; Rosenberger, 2010; Fleagle, 2013; Rosenberger and Tejedor, 2013). Due to this controversial taxonomy, in this study we do not include Patagonian fossil mandible specimens in the sample, considering only the generally accepted crown platyrrhine clade and its fossils.
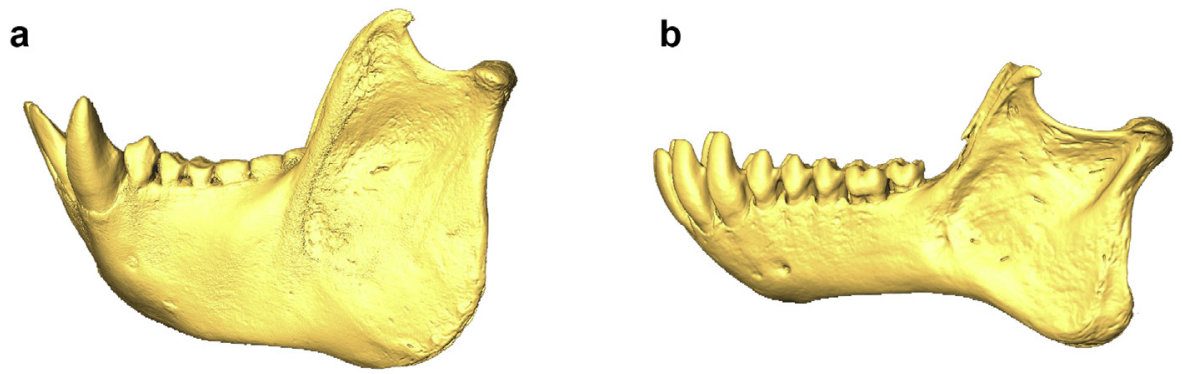

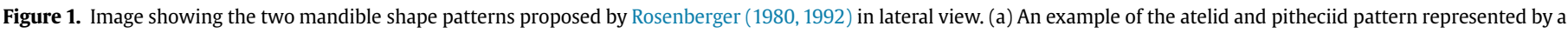
Cacajao calvus mandible specimen. (b) An example of the cebid pattern represented by a Callithrix penicillata mandible specimen. 
Younger platyrrhines found from the site of La Venta in the Magdalena River valley of Colombia, which date from the middle and late Miocene (10-14 Ma), present a different picture. This primate fauna is essentially of Amazonian aspect, including genera that probably represent the ancestors or close relatives of several living genera; they can certainly be allocated to existing low-level taxonomic clades - subfamilies and tribes (e.g., Hartwig and Meldrum, 2002; Rosenberger et al., 2009). The locality of La Venta has yielded several fossil platyrrhines, including Nuciruptor rubricae, believed to belong to the pitheciine clade (Meldrum and Kay, 1997), Aotus dindensis, the mandible morphology of which strikingly resembles that of extant Aotus (Setoguchi and Rosenberger, 1987), Neosaimiri fieldsi, similar to extant Saimiri (Takai, 1994), Lagonimico conclutatus, described by Kay (1994) as a giant tamarin, although Rosenberger (2002), based on mandible morphology, allocated this species to the pitheciine clade, and Laventiana annectens, similar to Neosaimiri and extant Saimiri (Rosenberger, 1984).

Platyrrhine evolution is also documented by several Pleistocene and Holocene fossils, mostly found in caves in Brazil and the Caribbean. There are well represented skeletal remains of the atelids Cartelles coimbrafilhoi (Halenar and Rosenberger, 2013) and Caipora bambuiorum (Cartelle and Hartwig, 1996; Fleagle and Tejedor, 2002; Fleagle, 2013), both from Brazil. Other Pleistocene and recent fossils have been recovered from different islands of the Caribbean, though their evolutionary relationships are disputed. Here we summarize our perspective of Caribbean monkey phylogeny (for alternative hypotheses see Kay, 2015). Xenothrix mcgregori, known from the latest-Pleistocene and perhaps recent remains found in Jamaica, is a difficult taxon, but prior studies (Rosenberger, 2002; Cooke et al., 2011) coalesce around the idea that X. mcgregori was a Jamaican monkey broadly related to Aotus (see Rosenberger et al., 2013). The Pleistocene-recent Antillothrix bernensis from the Dominican Republic is included in the piteciid clade due primarily to its mandibular morphology (Rosenberger et al., 2013). The Pleistocene Paralouatta varonai (the genus also represented by a bone of Miocene age), from Cuba, was a large platyrrhine thought, based on the cranium, to be part of the alouattin clade (Rosenberger et al., 2009). Some authors suggest that these Caribbean primates belong to a single monophyletic clade, Xenothrichidae (see Hershkovitz, 1974; Macphee and Fleagle, 1991), while others support various dispersal events from the nearby mainland, with millions of years of independent evolution between Caribbean and mainland platyrrhines (e.g., Rosenberger, 2002).

In this study, we quantitatively examine the hypothesis of an early morphological diversification of the platyrrhines through an analysis of morphometric variation in the mandible of extant and fossil species, and compare the results to those obtained using a phylogenetic comparative approach based on extant species. Particularly, we explore the phylogenetic structure and the pattern of morphological diversification through time. To test the hypothesis of early morphological diversification and evolutionary stasis in mandibular morphology, we use a molecular phylogeny of the extant platyrrhines estimated using a dataset of multiple coding and non-coding DNA sequences (Perelman et al., 2011; Aristide et al., 2015a), geometric morphometric techniques to study shape variation of the mandible (Mitteroecker and Gunz, 2009), and phylogenetic comparative methods (Blomberg et al., 2003; Harmon et al., 2003). This combination of phylogenetic comparative methods applied to extant species and the direct study of the fossil and extant taxa is considered one of the most efficient approaches to explore the pattern of morphological diversification of a clade (Gavrilets and Losos, 2009; Alvarez et al., 2011).

\section{Materials and methods}

\subsection{Samples}

Two different datasets were used, both based on digital images (see protocol below) from which landmark coordinates were collected. The first dataset consisted of 252 adult mandibles from 32 extant species belonging to the five main platyrrhine clades (Atelidae, Pitheciidae, Callitrichinae, Cebinae and Aotinae; Table 1, Supplementary Online Material [SOM] Table S1). Aotinae, a controversial taxon usually including only the extant genus Aotus, is employed here to minimize confusion with current literature. See Rosenberger and Tejedor (2013) for an alternative view of its systematics and classification. The specimens were obtained from the Mastozoology Sections of Museo de La Plata (MLP), Museo Argentino de Ciencias Naturales "Bernardino Rivadavia" (MACN), the Museu Nacional do Rio de Janeiro (MNRJ) and the American Museum of Natural History (AMNH). The second dataset included nine hemi-mandibles from fossil specimens obtained from images of casts and published reports (Table 2, SOM Table S2; Setoguchi and Rosenberger, 1987; Kay, 1994; Meldrum and Kay, 1997; Hartwig and Meldrum, 2002; Rosenberger et al., 2012, 2013). While our basic photographic protocol (see SOM) for producing digital images for this project was not followed in the publications cited, the hemi-mandible is a relatively flat structure in platyrrhines, therefore, the two-dimensional coordinate dataset faithfully captures comparable, pertinent shape information without bias (more information about error and reliability is given below). When possible, we examined more than one photograph of each fossil specimen, including a published photograph of the original specimen and an image of the cast taken for us, to be confident about

Table 1

Extant species sample used in the morphometric analyses.

\begin{tabular}{|c|c|c|c|}
\hline Species & $n$ & Clade & Institution $^{\mathrm{a}}$ \\
\hline Aotus azarae & 18 & Aotinae & MACN \\
\hline Aotus nigriceps & 5 & Aotinae & MNRJ \\
\hline Alouatta caraya & 20 & Atelidae & MACN \\
\hline Alouatta palliata & 2 & Atelidae & MACN \\
\hline Ateles belzebuth & 3 & Atelidae & MACN \\
\hline Brachyteles arachnoides & 4 & Atelidae & MNRJ \\
\hline Brachyteles hypoxanthus & 2 & Atelidae & MNRJ \\
\hline Lagothrix lagotricha & 3 & Atelidae & MACN \\
\hline Leontopithecus rosalia & 6 & Atelidae & MACN \\
\hline Callimico goeldii & 1 & Callitrichinae & MNRJ \\
\hline Callithrix jacchus & 22 & Callitrichinae & AMNH; MACN \\
\hline Callithrix penicillata & 4 & Callitrichinae & MNRJ \\
\hline Leontopithecus chrysomelas & 4 & Callitrichinae & MNRJ \\
\hline Mico argentatus & 1 & Callitrichinae & MACN \\
\hline Mico chrysoleucus & 4 & Callitrichinae & MNRJ \\
\hline Saguinus fuscicollis & 6 & Callitrichinae & MACN \\
\hline Cebuella pygmaea & 1 & Callitrichinae & MNRJ \\
\hline Cebus albifrons & 8 & Cebinae & MACN \\
\hline Cebus apella & 4 & Cebinae & MACN; MLP \\
\hline Cebus libidinosus & 20 & Cebinae & MACN \\
\hline Cebus nigritus & 8 & Cebinae & MACN \\
\hline Saimiri boliviensis & 9 & Cebinae & MACN \\
\hline Saimiri sciureus & 2 & Cebinae & MACN \\
\hline Cacajao calvus & 3 & Pitheciidae & MNRJ \\
\hline Cacajao melanocephalus & 4 & Pitheciidae & MNRJ \\
\hline Callicebus donacophilus & 12 & Pitheciidae & MACN \\
\hline Callicebus personatus & 5 & Pitheciidae & MNRJ \\
\hline Chiropotes albinasus & 10 & Pitheciidae & AMNH \\
\hline Chiropotes satanas & 28 & Pitheciidae & AMNH \\
\hline Pithecia irrorata & 21 & Pitheciidae & AMNH \\
\hline Pithecia pithecia & 8 & Pitheciidae & AMNH \\
\hline Saguinus midas & 4 & Pitheciidae & AMNH \\
\hline TOTAL & 252 & & \\
\hline
\end{tabular}

a Abbreviations defined in text. 
landmark placements. The fossils represent at most nine different genera (Table 2). Five of these species (A. dindensis, L. conclutatus, $L$. annectens, $N$. fieldsi and $N$. rubricae) were recovered at La Venta. These fossils can be easily allocated to modern platyrrhine groups (e.g., Hartwig and Meldrum, 2002). The other four species are Pleistocene to Holocene in age and come from the Caribbean or east central Brazil: A. bernensis, X. mcgregori; P. varonai; C. bambuiorum.

\subsection{Phylogenetic data}

Phylogenetic trees have direct or indirect interest for several branches of biology and anthropology (e.g., Lemey et al., 2009; Wiens, 2009; Yang and Rannala, 2012) and their estimation is a necessary first step for understanding the factors responsible for the ecological and phenotypic diversification of a clade (e.g., Felsenstein, 1985; Wiens, 2009; Losos, 2011). In this study, we based our phylogenetic analysis on the fossil-calibrated chronophylogenetic tree previously published in Aristide et al. (2015a), obtained using Bayesian methods on a concatenated dataset of 25,361 DNA bp, including coding and non-coding sequences and selecting six fossil calibrations.

\subsection{Geometric morphometric analysis of extant and ancient specimens}

Geometric morphometric techniques were used to study variation in the mandibular morphology of extant and fossil platyrrhine species. Two-dimensional coordinates were captured from digital images of the left hemi-mandible in lateral view, standardizing these images for mandible and camera lens plane position and distance to camera lens (See SOM; Zelditch et al., 2004). In some cases, the left side was missing or damaged. This issue was solved by using the reflected image of the right side. tpsDIG 2.12 software (Rohlf, 2015) was used to digitize 41 two-dimensional coordinates of landmarks and semilandmarks (Fig. 2). Since several fossil specimens preserved only the mandibular corpus, a subset of eight landmarks and 10 semilandmarks was used to characterize its shape (Fig. 2; see SOM for landmark and semilandmark definitions). The mandibular corpus, comprising the horizontal ramus and the alveolar region from incisors to molars (Atchley and Hall, 1991 ) and, in this study also including the region that many researchers call the symphysis, is a well-defined anatomical module that makes an important contribution to morphological variation of the full mandible (Cheverud et al., 2004; Alvarez et al., 2011).

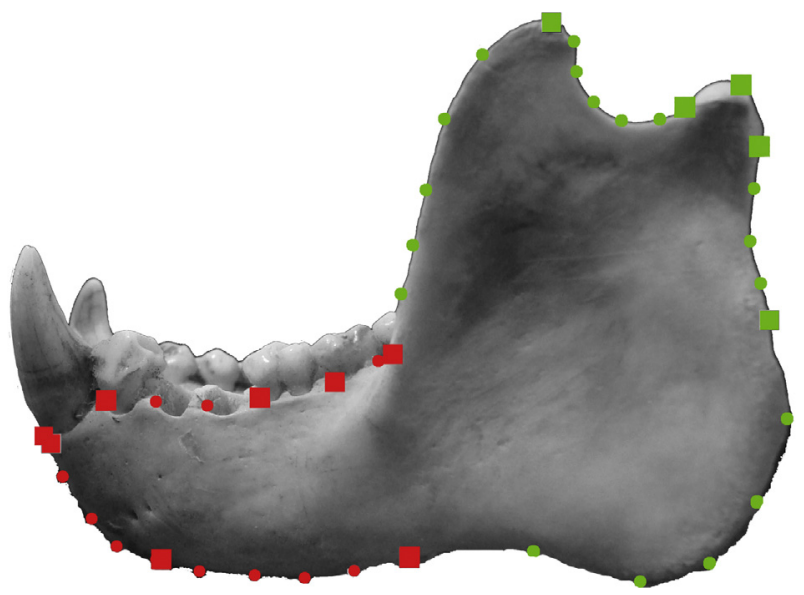

Figure 2. Mandible landmarks (squares) and semilandmarks (circles) recorded from New World monkeys using tpsDig. Red squares and circles were included in mandibular corpus analyses. (For interpretation of the references to color in this figure legend, the reader is referred to the web version of this article.)

Once the coordinates were recorded, the geomorph package (Adams and Otárola-Castillo, 2013) for R (R Development Core Team, 2015) was used to align the landmarks and semilandmarks by means of Generalized Procrustes analysis and the sliding method (with bending energy criterion; Perez et al., 2006; Gunz and Mitteroecker, 2013). This allowed us to eliminate variation due to differences in scaling, rotation and position of the specimens (i.e., non-shape variation) and to estimate the consensus shapes for each species, evaluating shape differences among them. The Procrustes shape coordinates resulting from the alignment were analyzed using principal component analysis (PCA) to reduce morphospace dimensionality. A PCA consists of the generation of uncorrelated axes describing major tendencies in shape variation within the sample. The resulting axes are lineal combinations of the original Procrustes coordinates derived from a rigid rotation of the morphospace. In this way the coordinates are not distorted during computation (Mitteroecker and Gunz, 2009). The estimation of the PCA was carried out with the extant species' mean shape or consensus.

We also performed a PCA including extant and fossil specimens. It was estimated by projecting the fossil specimens onto the extant consensus species' principal component (PC) space. For this, we first estimated a Generalized Procrustes superposition of the mandibular corpus shape coordinates belonging to extant

Table 2

Fossil specimens used in the morphometric analyses. ${ }^{\text {a }}$

\begin{tabular}{|c|c|c|c|c|}
\hline Specimen & Site information & Date & $\begin{array}{c}\text { Cast } \\
\text { available }\end{array}$ & Photo source \\
\hline Aotus dindensis & $\begin{array}{l}\text { Locality 9-86 A, El Dinde area, Tatacoa Desert, Huila } \\
\text { Department, Colombia. }\end{array}$ & Middle Miocene; $12-15$ Ma & Yes; AMNH & $\begin{array}{l}\text { Setoguchi and Rosenberger } \\
\text { (1987) }\end{array}$ \\
\hline $\begin{array}{l}\text { Lagonimico } \\
\text { conclutatus }\end{array}$ & $\begin{array}{l}\text { Locality 90, La Victoria Formation, Tatacoa Desert, } \\
\text { Huila Department, Colombia. }\end{array}$ & Middle Miocene; $\approx 13.5 \mathrm{Ma}$ & No & Kay (1994) \\
\hline $\begin{array}{l}\text { Laventiana } \\
\quad \text { annectens }\end{array}$ & $\begin{array}{l}\text { Masato Site, Villavieja Formation, La Venta Area, } \\
\text { Huila Department, Colombia }\end{array}$ & Middle Miocene; $10-12.5 \mathrm{Ma}$ & Yes; AMNH & Hartwig and Meldrum, 2002 \\
\hline Neosaimiri fieldsi & $\begin{array}{l}\text { Honda Group, Villavieja Formation, La Venta Area, } \\
\text { Huila Department, Colombia }\end{array}$ & Middle Miocene; $12-16 \mathrm{Ma}$ & Yes; AMNH & Hartwig and Meldrum, 2002 \\
\hline Nuciruptor rubricae & $\begin{array}{l}\text { Duke Locality 32, Honda Group, Villavieja Formation, } \\
\text { La Venta Area, Huila Department, Colombia }\end{array}$ & Middle Miocene $12.8 \pm 0.2 \mathrm{Ma}$ & No & Meldrum and Kay (1997) \\
\hline Antillothrix bernensis & $\begin{array}{l}\text { La Jeringa Cave, Parque Nacional del Este, La Altagracia } \\
\text { Province, Dominican Republic }\end{array}$ & Late Holocene; $3850 \pm 150 \mathrm{BP}$ & Yes; AMNH & Rosenberger et al. (2013) \\
\hline Caipora bambuiorum & Toca da Boa Vista Cave, Bahia State, Brazil & Pleistocene/recent & No & Rosenberger et al. (2012) \\
\hline Paralouatta varonai & Cueva Alta, Cuba & Early Quaternary & Yes, AMNH & Macphee and Horovitz (2008) \\
\hline Xenothrix mcgregori & Long Mile Cave, Jamaica & Quaternary, until $\approx 1700 \mathrm{AD}$ & No & Rosenberger (1977) \\
\hline
\end{tabular}

${ }^{\mathrm{a}} \mathrm{BP}=$ Before Present; AMNH = American Museum of Natural History. 
consensus species and fossil specimens all together, obtaining the Procrustes coordinates corresponding to both samples. We then subtracted the fossil specimens' coordinates and generated a PC space with the extant species only. This way, the obtained space represents the major patterns in mandible variation for the extant species only, without influence from the fossil species. As a final step, the shape data of fossil specimens were projected onto this PC space. To better describe the shape differences among extant and fossil species, we estimated a Minimum Spanning Tree (MST) based on the Euclidean distance (total shape variation) matrix and displayed it on the PC1 plus PC2 morphospace. Additionally, we calculated between-group PCs (Mitteroecker and Bookstein, 2011) to better describe the shape variation within species. In this analysis we used the consensus of extant species to generate the PC shape space and then projected all the specimens, both extant and fossils. All the procedures were performed using the geomorph (Adams and Otárola-Castillo, 2013) and stats package for R ( R Development Core Team, 2015).

Finally, to examine the range of morphological variation in living and fossil taxa, we calculated Foote's disparity measurement ( $D$, Foote, 1993; Neige, 2003) and the variance of the Procrustes distances $(V)$, a measure similar to $D$. The $D$ is estimated as the distance from the mean shape of each species to the consensus mean shape of all species. Conversely, the variance is calculated directly over the column of Euclidean distances between the studied species. Also, confidence intervals were obtained by means of bootstrap iterations, as implemented in the geomorph $\mathrm{R}$ package.

\subsection{Measurement error}

We assessed measurement error through Procrustean Randomization Test (PROTEST), a permutation test used for comparing multivariate data sets by means of a Procrustes statistic, minimizing the sum-of-squared differences between configurations in a multivariate space, followed by the randomization and permutation of values between sets and the posterior estimation of the statistical significance of the Procrustean fit (Peres-Neto and Jackson, 2001). We carried out four distinct PROTEST analyses to evaluate a) intraobserver error due to landmark and semilandmark digitizing; b) error associated with mandible orientation; c) differences between two or three-dimensional datasets; and d) error related to the use of images obtained from publications and fossil casts. For the intraobserver error estimation, a single set of 17 photographs of platyrrhine mandible specimens in lateral view (each corresponding to a different genus) was used to digitize landmarks and semilandmarks in two distinct sessions separated by a two week period. To test error due to orientation we digitized landmarks and semilandmarks in two datasets, containing the same 17 platyrrhine mandible specimens in each set, differing in their orientation: the first dataset was oriented aligning the sagittal plane in parallel with the camera lens, while in the second set the mandibular corpus was parallel to the lens. To analyze differences between the use of two or threedimensional mandible samples (see Alvarez and Perez, 2012), we digitized landmarks and semilandmarks onto two datasets of 34 mandible specimens each (two per genus). The first set was threedimensional, and the second sample was two-dimensional. For this analysis we employed a sample of Computed Tomography (CT) scans obtained in the Mastozoology Sections of Museo de La Plata (MLP), Museo Argentino de Ciencias Naturales "Bernardino Rivadavia" (MACN) and the Digital Morphology Museum of the Kyoto University Primate Research Institute (DMM, KUPRI). Finally, to test the error due to the use of images obtained from publications and fossil casts, we used two datasets containing the same specimens but differing in the source from which they were obtained. One sample was based on original published images and the other was based on our own photographs of casts. We performed a Procrustes fit on the coordinates taken during each sampling and compared the ordinations produced by each. As a measure of association we used the sum of the squared residuals corresponding to each ordination (Gower, 1971; Perez et al., 2006). Finally, to test the statistical significance of the Procrustean fit we carried out the permutation procedure PROTEST (Jackson, 1995; Peres-Neto and Jackson, 2001). Procrustes analysis and PROTEST were implemented using geomorph (Adams and Otárola-Castillo, 2013) and vegan (Oksanen et al., 2014) packages for R v3.3.1.

\subsection{Phylogenetic comparative analysis of extant specimens}

We first tested for the association between size and mandible shape variation among extant species using a Phylogenetic Generalized Least-Square (PGLS) analysis, which takes into account the expected lack of independence among species (Martins and Hansen, 1997; Rohlf, 2001). We fit the PC scores of shape coordinates to the Log-Body Mass (Log-BM; Aristide et al., 2015a) using the regression model: $\mathrm{S}=\mathrm{XB}+e$, where $\mathrm{S}$ is the $\mathrm{PC}$ score matrix describing mean differences between species, $X$ is the Log$\mathrm{BM}$ matrix, $\mathrm{B}$ is the matrix of partial regression coefficients, and $e$ is the error term. To account for phylogenetic non-independence, this regression analysis assumes that $e$ has a covariance matrix (C) derived from the phylogenetic tree of the studied species (Martins and Hansen, 1997; Rohlf, 2001). The PGLS analysis was run using the package caper (Orme, 2013) in the software R.

In order to examine the relationship between phylogeny and phenotypic variation in the mandible, we measured the phylogenetic signal of jaw morphology among extant platyrrhine species. Phylogenetic signal is the tendency of more closely related species to be more similar with respect to a given trait than more distantly related species; expressed in another way, it is a measure of the statistical dependency between the trait value and the phylogenetic tree. Since we used multidimensional data (Procrustes shape coordinates), we estimated a multivariate generalization of Blomberg's $K$ statistic, $K_{\text {mult }}$ method, which is used for quantifying and evaluating phylogenetic signal in multidimensional traits like shape under a Brownian motion evolutionary model (Blomberg et al., 2003; Adams, 2014). We also estimated the Blomberg's $K$ statistic on the scores from PC axes 1 and 2. The phylogenetic signal was calculated using the picante (Kembel et al., 2010) and geomorph (Adams and Otárola-Castillo, 2013) packages in R.

With the objective of visualizing changes in shape variables of the mandibular corpus and the hemi-mandible during phylogenetic history, we mapped and plotted the extant species PC1 scores on the estimated phylogenetic tree in .nwk format, estimating ancestral character states through a maximum likelihood (ML) based procedure, which assumes that characters evolve under a Brownian motion model. This way, two species will be expected to be different from one another in proportion to the time elapsed since sharing a common ancestor (Felsenstein, 1985). The ML estimate of the root is equivalent to the root node estimated during a contrasts algorithm, so, by re-rooting the tree at each node, ML at every node in the tree was calculated. The mapping of PC1 scores on the phylogenetic tree was carried out using the phytools (Revell et al., 2012) package for $\mathrm{R}$.

To visualize the phenotypic variation pattern of the mandible within and among the platyrrhine clades through their phylogenetic history - including time and branching pattern - we generated a disparity-through-time (DTT) plot using a platyrrhine 
chronophylogenetic tree in.$n w k$ format and extant species PC scores, for PC1 and for PC1 and PC2 together. Disparity can be estimated using the mean Euclidean distances between species. It is calculated for each clade as a whole, and then for each subclade defined by a node in the phylogeny. Then, the relative disparity is calculated as the subclade disparity in relation to the whole disparity. Relative mean disparity - in other words the average of all relative disparities from all subclades whose ancestral lineages were present at the moment of divergence - was estimated for every divergence event through the phylogeny. Relative disparity values near to 0 imply that subclades contain relatively less variation than the clade's total variation. Values close to 1 imply that subclades include a substantial proportion of total variation of the clade (Harmon et al., 2003). In an early niche-filling scenario (i.e., the adaptive radiation or Simpsonian ecospace model) for platyrrhines, we would expect phenotypic disparity to be split among the main subclades (i.e., the subfamilies). The DTT analysis was performed using the geiger package (Harmon et al., 2008) for R.

\section{Results}

The results of the PROTEST procedure for measurement error associated with intra-observer error showed a statistical significance of the Procrustean fit between both ordinations (Fit Correlation value $=0.9865, p<0.001$ ), indicating that the differences between measurement sessions are not statistically significant. Moreover, our second PROTEST analysis testing measurement error related to distinct mandible orientations also showed high correlation between ordinations $(0.9676, p<0.001)$, suggesting the nonsignificance of such differences. Since the mandible is relatively flat yet still contains three-dimensional structure, we tested the error between 2D and 3D measurements with a PROTEST analysis as well. This result showed a Procrustes correlation of $0.9991(p<0.001$; SOM Fig. S1), suggesting that the differences due to the number of dimensions registered is not significant. Finally, the results of the PROTEST analysis between published images and the photographs of fossil casts displayed a high correlation $(0.9923 ; p<0.001)$, suggesting that both datasets are useful for these morphometric analyses.

In the PC analysis based on the complete mandibles of the living species, the first two PCs explain about $64 \%$ of total variation (PC1: 47.39\%; PC2: 16.89\%; Fig. 3a). The major differences in morphology involve the changes in the relative size of angular region, which is smaller toward the most positive values of PC1. The mandibular corpus uncovers variation related to its dorsoventral height, which is more compressed for the most positive values of PC1. The subfamily Callithricinae (specifically Cebuella pygmaea) is located on the extreme edge of PC1, though the cluster shows a large spread along both PC axes. On the opposite end of PC1 are the pithecids and the atelids with a deeper mandibular corpus, combined with a larger angular region. The most negative values on PC1 belong to Callicebus donacophilus and Alouatta caraya. The Pitheciidae are located toward the positive end of PC2, while all Atelidae fall into negative values. The spread of Cebinae reflects a clear division between Cebus and Saimiri species, the latter showing more positive values on PC1 and negative values on PC2, while Cebus species exhibit intermediate values on PC1 and positive values on PC2. Also, Saimiri species fall within the Callitrichinae morphospace. Aotinae are located between Pitheciidae and Cebus species, with negative values on PC1 and positive values on PC2. Aotus exhibits a larger angular process, and a more dorsoventrally compressed mandibular corpus. The wide separation displayed between the two Aotus species is noteworthy, since Aotus azarae falls closer to pithecids and Aotus nigriceps closer to cebids, suggesting that the two opposite phylogenetic hypotheses regarding its position within the platyrrhines (see Rosenberger and Tejedor, 2013) are represented in the shape data. The PGLS results show that shape variation of complete mandibles (PC1-6 [ 90\% of shape variation]) is not strongly associated with variation in body size $\left(\mathrm{R}^{2}=0.14 ; p=0.02\right)$, although the association is stronger when we consider the variation in PC1 $\left(\mathrm{R}^{2}=0.45 ; p<0.001\right)$ or PC1 plus PC2 $\left(\mathrm{R}^{2}=0.49 ; p<0.001\right)$.

The results of the PCA of the mandibular corpus of living species showed that the first two PCs explained $65 \%$ of total variation (PC1: 35.83\%; PC2: 29.85\%; Fig. 3b). The most significant morphological differences are in the relative dorsoventral height of the mandibular corpus, which is relatively more compressed for the most positive values of PC1. The species' distribution along PC1 is similar to that displayed on the PCA of the complete mandible, though there is a difference in the position of the atelids, which display more intermediate values on this axis. This apparently indicates that mandibular corpus morphology is an acceptable discriminator between this family and the pitheciids. Moreover, aotines, with intermediate values on PC1 and positive values on PC2, are located inside the atelid distribution in morphospace. Pitheciids, with a more expanded mandibular corpus, display a wide distribution along PC2, thus marking a difference with the previous PCA based on the complete mandible. The PGLS results show that shape variation of the mandibular corpus (PC1-4 [ 90\% of variation]) is not associated with variation in body size $\left(\mathrm{R}^{2}=0.005 ; p=0.68\right)$, the PC1 plus PC2 display a very low association with Log-BM $\left(\mathrm{R}^{2}=0.10\right.$; $p<0.04)$, and the PC1 shows a significant but relatively low association with $\log -\mathrm{BM}\left(\mathrm{R}^{2}=0.23 ; p<0.003\right)$. Thus, even though the results are significant, $\mathrm{R}^{2}$ values are too low to seriously consider this association in future discussions.

Summarizing, results of the PC analyses of the complete mandible and the mandibular corpus of the extant species reveal a large amount of morphological variation. Additionally, the distribution pattern of the species in morphospace allows us to infer the existence of a marked phylogenetic structure in platyrrhine mandibular morphology. The quantified phylogenetic signal for the extant species mandibular corpus based on multivariate data (Procrustes shape coordinates, $K_{\text {mult }}=0.479 ; p=0.001$ ) implies that the taxa are phenotypically less similar to each other than expected under Brownian motion (Adams, 2014). The $K$ statistic for univariate data for PC1 $(K=1.518 ; p=0.001)$ and PC2 $(K=0.818$; $p=0.001$ ) indicates a strong phylogenetic signal.

The mapping of the PC1 scores for the mandibular corpus on the phylogeny (Fig. 4), according to phylogeny and a Brownian motion model, estimated that the relatively short and deep mandibles of Pitheciidae may have appeared early in the clade's phylogenetic history ( 15-20 Ma), with negative values of PC1 at the node of this family origin. Among them, Callicebus and Chiropotes might seem to have evolved independently through a process of increased shortening and deepening of the mandible body. In the case of Chiropotes and Cacajao, corpus depth and robusticity is exaggerated. The atelids, as well as Aotus species, show intermediate values for PC1. Similarly, the cebine Saimiri and the callitrichines Cebuella, Callithrix, Mico and Callimico may have undergone a significant lengthening of the mandibular corpus while retaining the shallowest jaws among platyrrhines. It is important to highlight that this method estimates ancestral node values without using the information from the fossil record. Nevertheless, it is a remarkable tool for formulating new hypotheses on the platyrrhine past shapes, verifiable with the known fossil record.

The DTT-plots, obtained for PC1 only (Fig. 5a) and for the first two PCs obtained from extant species (Fig. 5b), indicate that the average disparity of mandibular morphology within the subclades is lower than the expected under a Brownian motion model as the evolution of platyrrhines unfolded. Both DTT-plots show that the average disparity values drop near 0 early in the crown platyrrhine 
a

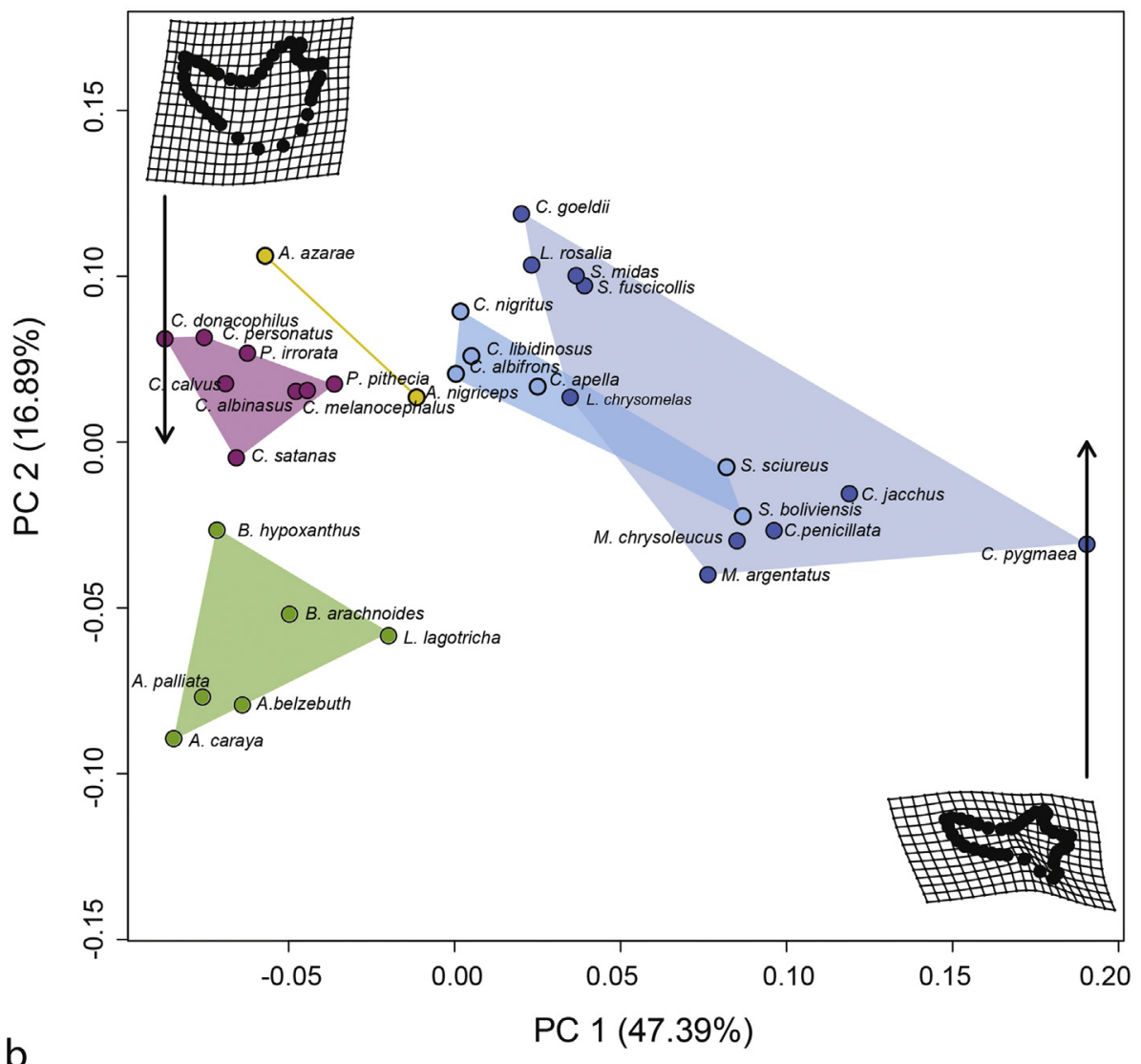

b

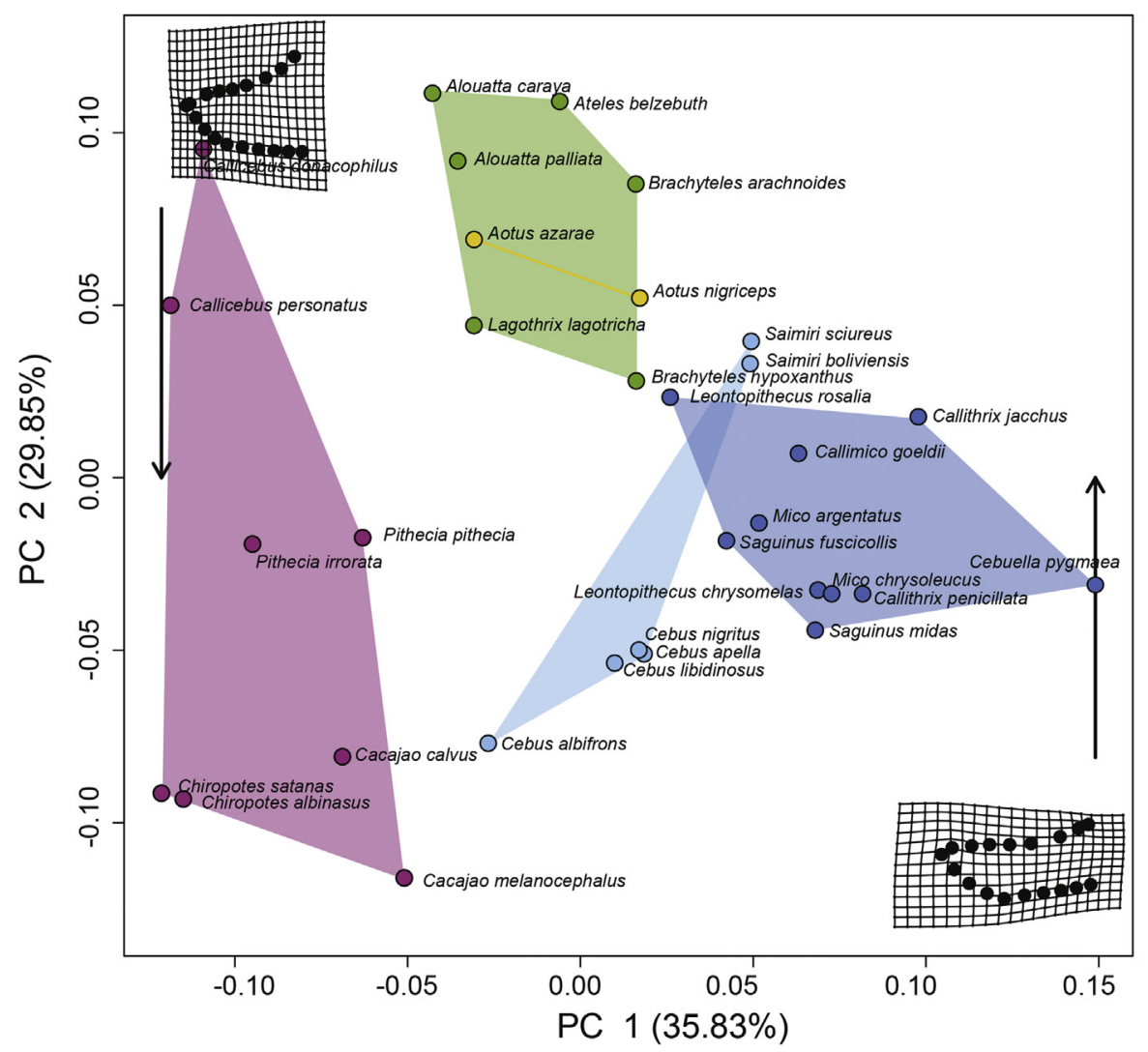

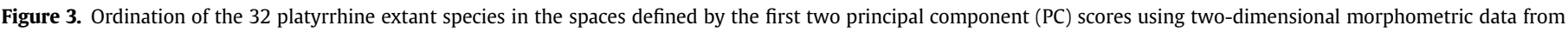

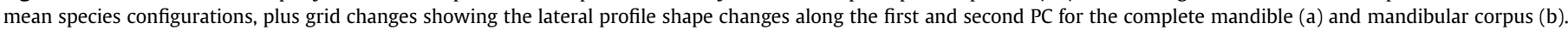
Dots represent a consensus individual for each species. Filled polygons indicate each extant family and subfamily. 

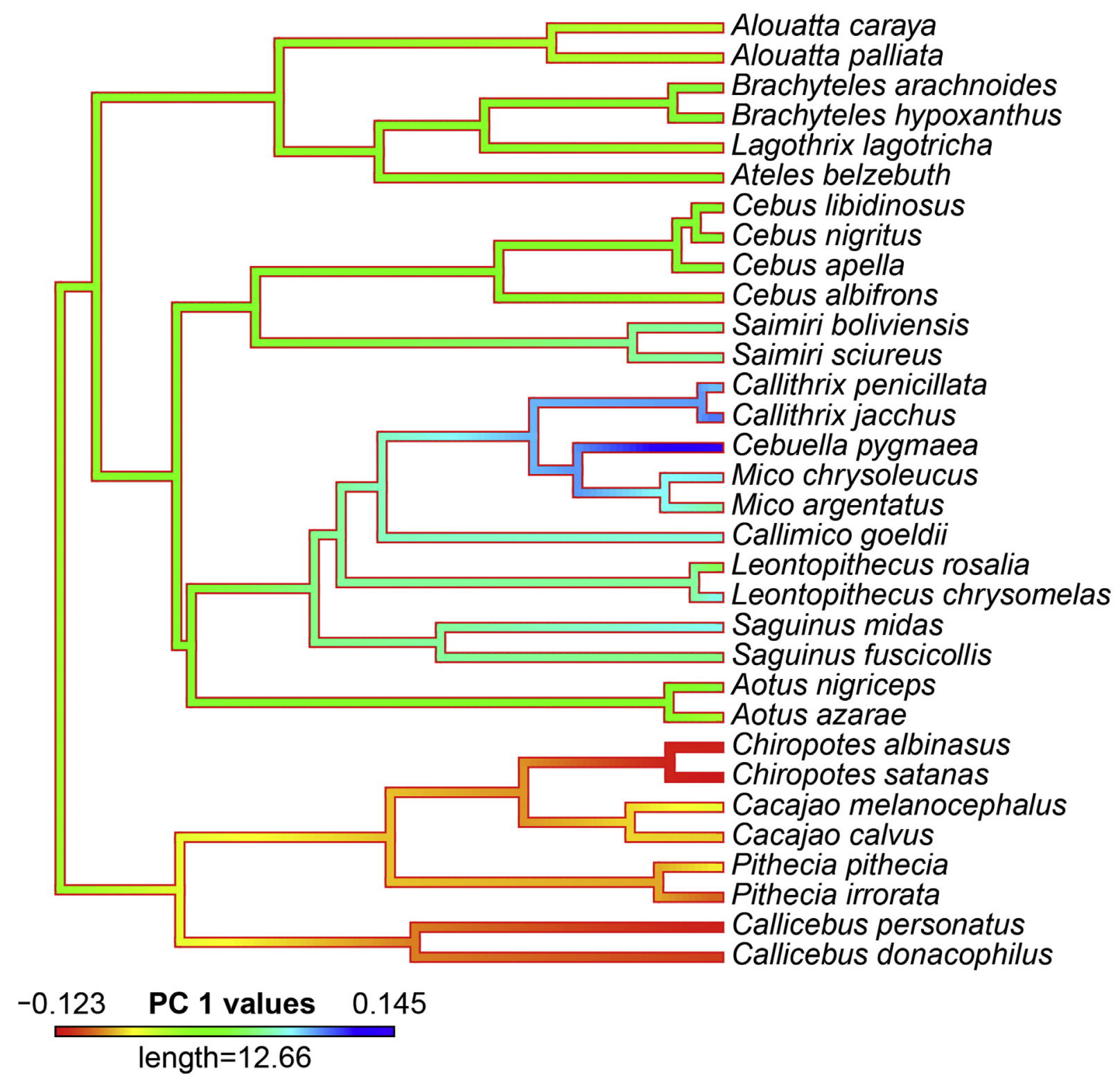

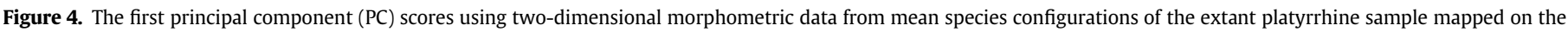

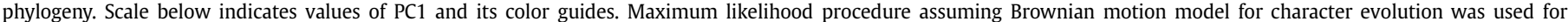

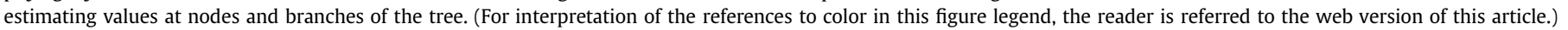

diversification, showing little variation through time. Particularly, examining PC1 and PC2, the DTT-plot suggests that the diversification in mandible shape among the main platyrrhine clades occurred 20-15 Ma (Fig. 5b). This means that most of the mandible shape variation that can be seen between the main platyrrhine subclades, which are clearly differentiated in morphospace, seems to appear as expected in a niche-filling paradigm, i.e., as in Simpson's model. Thus, morphological differentiation between subclades might have arisen close to the origin of the crown platyrrhine taxon.

The PCA performed with extant consensus species and the posterior projection of the fossils' morphological data (Fig. 6) showed that the first two PCs explain about $69.5 \%$ of total variation (PC1:42.55\%; PC2:26.98\%; Fig. 6). The distribution of species in shape space is similar to the ordination along PC1 and PC2 of analysis of extant species. The analysis shows that some of the La
Venta fossils ( $N$. rubricae, $N$. fieldsi, L. annectens, A. dindensis) are located near callitrichines and cebines, while Pleistocene/Holocene fossils and $L$. conclutatus are positioned closer to the atelids and aotines. The position of $A$. dindensis in PC space, which overlaps with that of Callithrix jacchus, is relatively separated from extant Aotus species and closer to N. fieldsi and Mico, Leontopithecus and Saguinus species. Moreover, the MST gave us a better view of shape relationships among other species, which are only approximated in the reduced morphospace described by PC1 and PC2. In particular, N. rubricae is also close to Mico, Leontopithecus and Saguinus species and $A$. bernensis is close to X. mcgregori and to extant atelids, although they seem distant in the PC1 plus PC2 morphospace (Fig. 6). The between group PCA projecting the individual observations on the morphospace of the species mean shape (excluding fossils) shows that the fossil specimens are within the range of variation expected for current families (Fig. 7). 
a

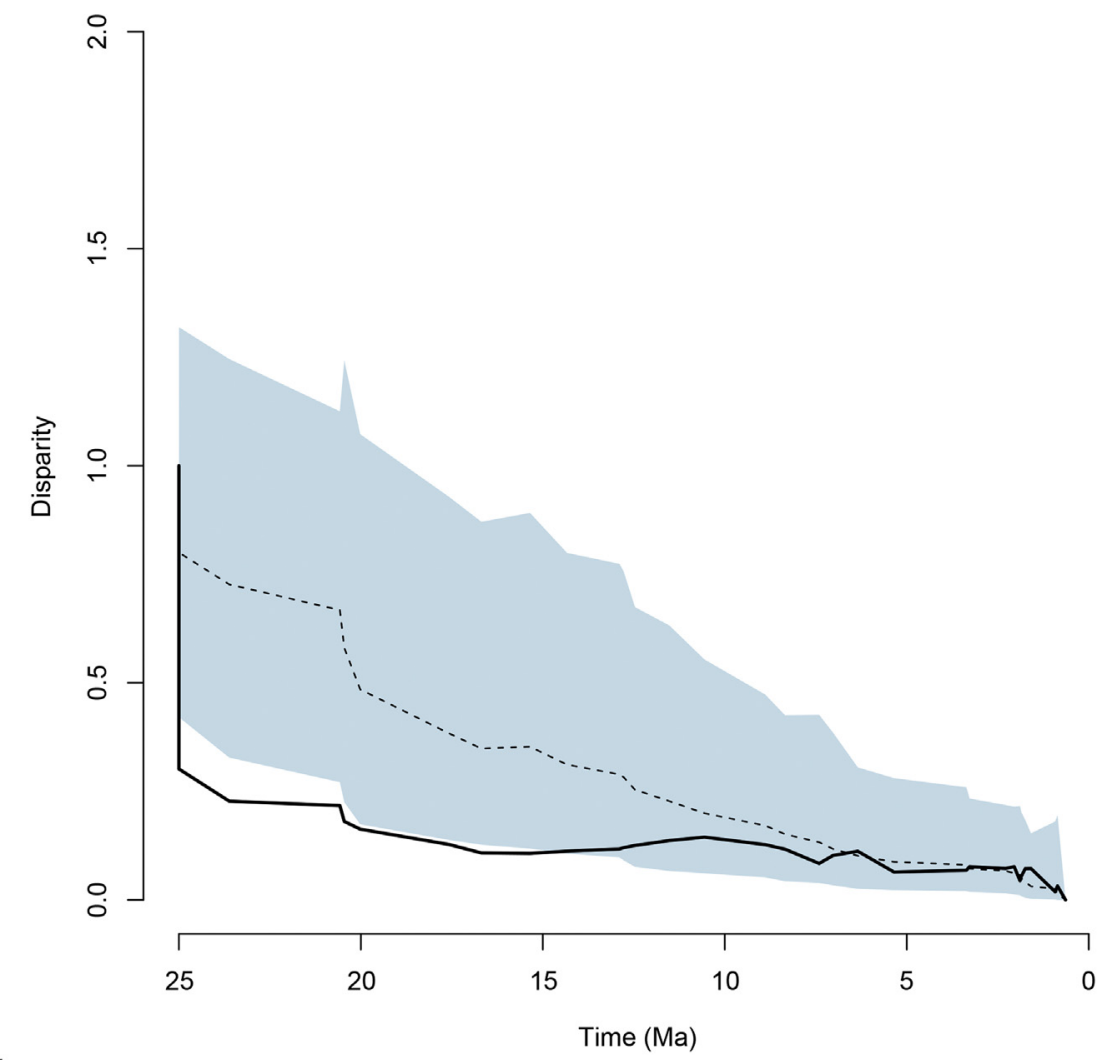

b

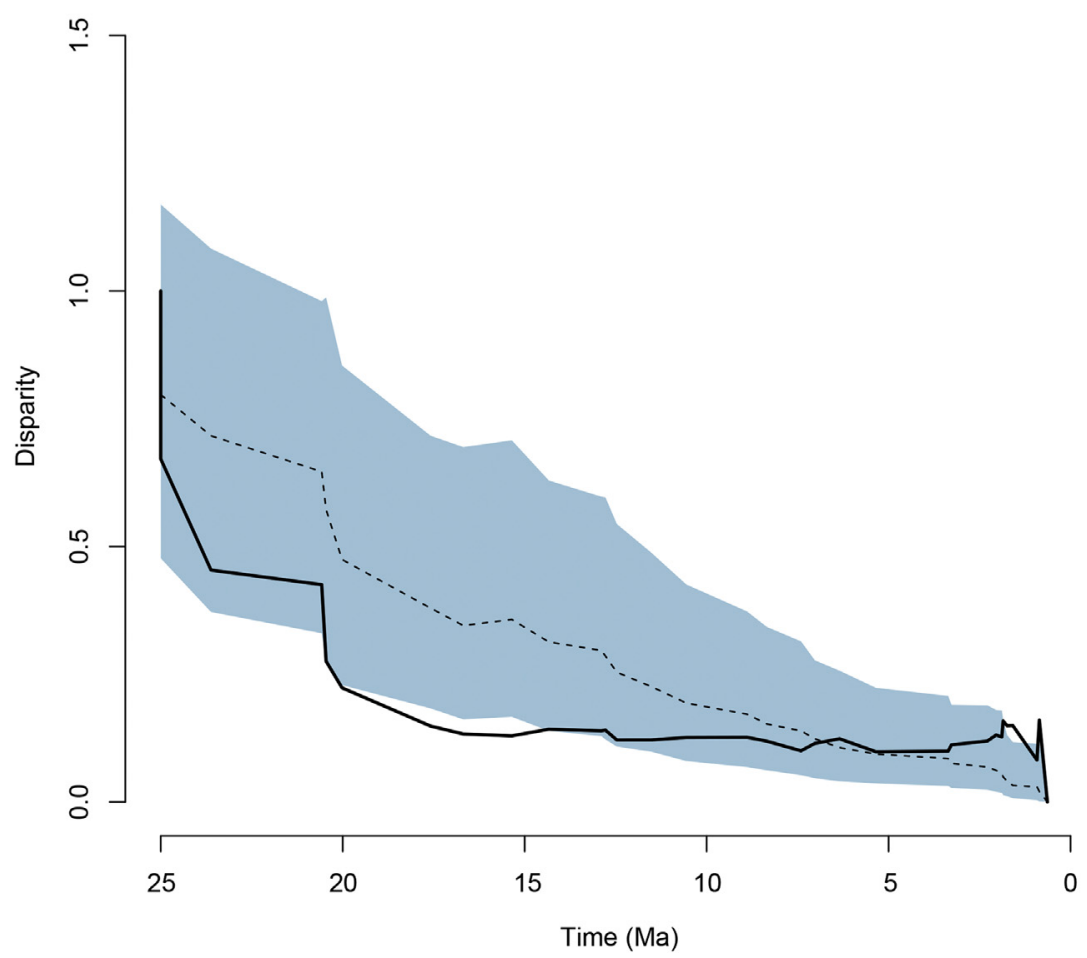

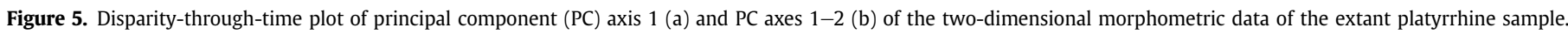

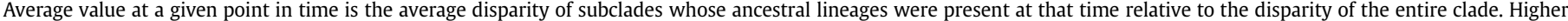

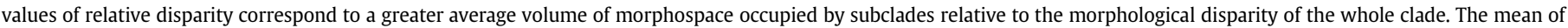

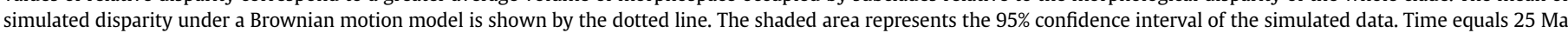

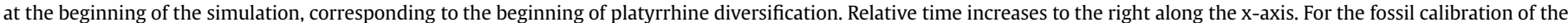
phylogenetic tree used on this analysis, six fossils were used (see Aristide et al., 2015a). 


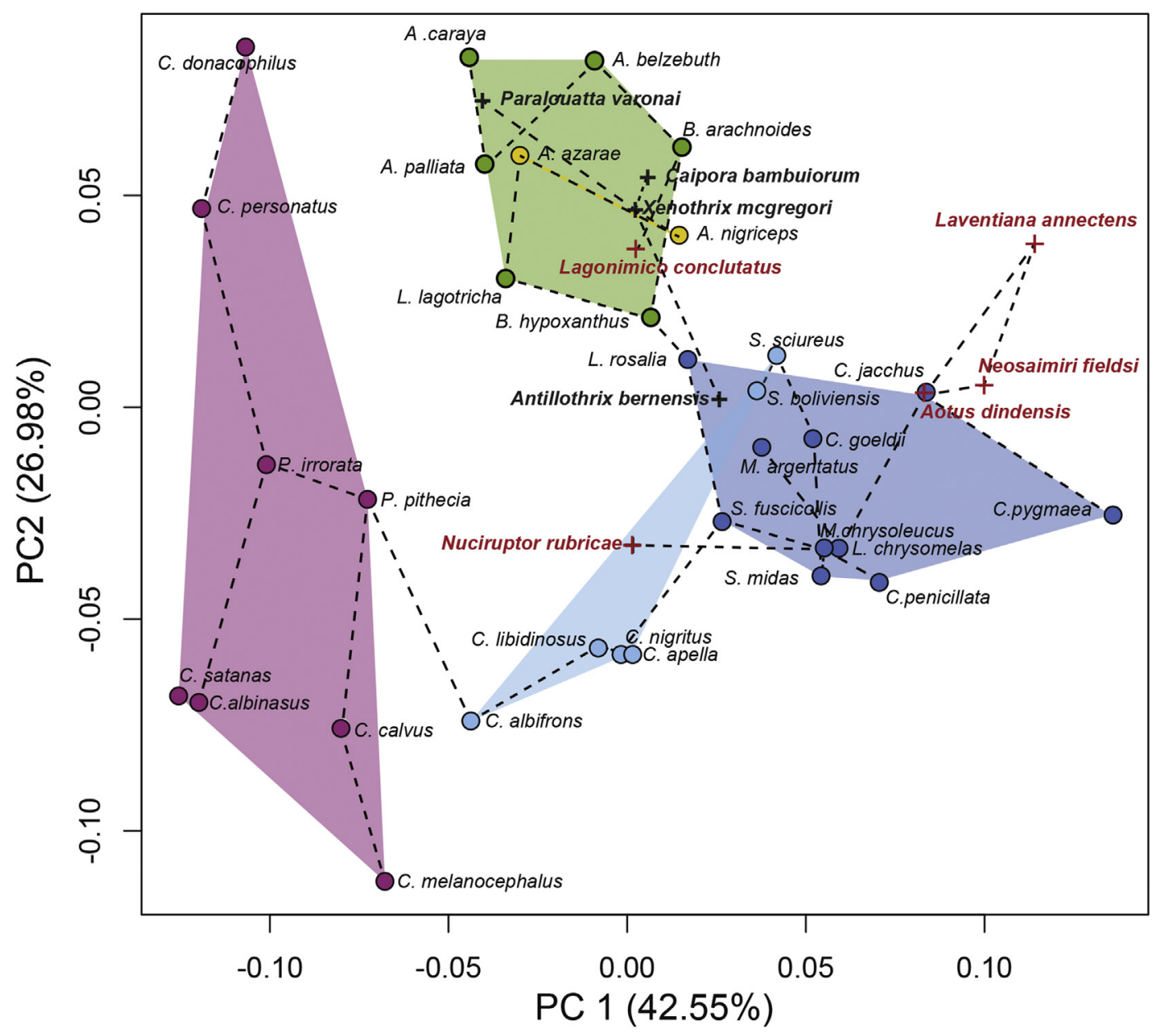

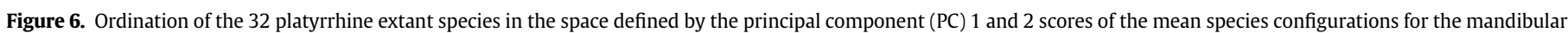

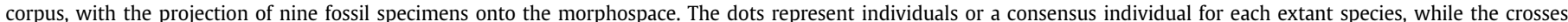

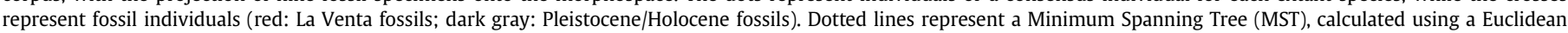

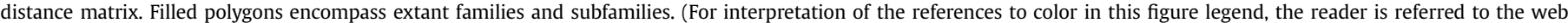
version of this article.)

\section{Discussion}

In recent years, the origin and maintenance of morphometric variation among platyrrhine species, as also found in other clades, have been mainly studied using a statistical (phylogenetic) comparative approach on extant species (e.g., Perez et al., 2009, 2011; Mahler et al., 2010). We show that it is important to analyze extant and fossil morphological data, since it allows us to consider past morphological variation in relation to extant species variation. Although several efforts previously used this type of sampling to calculate the age of lineages, species origination and extinction rates, or changes in body size among past platyrrhine species (Fleagle and Tejedor, 2002; Perez et al., 2013; Aristide et al., 2015a), our report is one of the first to include fossil evidence in the morphometric and phylogenetic comparative analyses in platyrrhines.

As in previous studies analyzing the mandibles of fossil and extant species from other mammalian clades (e.g., Alvarez et al., 2011), the relatively poor preservation of fossil platyrrhine mandibles made it difficult to analyze this structure beyond the corpus or alveolar region. However, the results obtained were similar to the results obtained analyzing the mandible as a whole. Moreover, we are encouraged that the pattern of shape variation among the hemi-mandibles of extant genera described in two dimensions did not differ significantly from the picture obtained with the hemi- mandibles in three dimensions. In several ways, our quantitative analysis also corresponds well with previous trait analyses of mandible evolution (Rosenberger, 1977, 1992; Tejedor and Rosenberger, 2008; Rosenberger and Tejedor, 2013). Despite the fact that some forms of variation were not considered in this study, for example the relative size of the mandibular corpus and ramus (which has been of considerable importance for describing certain primate groups; Rosenberger and Tejedor, 2013), or the effects of taphonomy on the fossils, our results suggest that the use of mandibular corpus morphometric data in two dimensions, including previously published mandible images of fossil specimens, is adequate to describe patterns of mandibular variation in the platyrrhine species.

Regarding the fossils, several findings are highly interesting (Figs. 6 and 7). There are consistent clusterings in morphospace, also evident in the MST. Paralouatta is associated with Alouatta among atelids, Caipora and Lagonimico fall close to Brachyteles among atelids, and Xenothrix and Antillothrix align close to one another and in association with aotines and atelids. These are species with atelid- or primitive pitheciid-style (e.g., roughly Pithecia-like) mandibles. Placement of Laventiana and Neosaimiri toward the extreme end of the cebid distribution also corresponds with predictions based on character analysis, and the position of Neosaimiri fairly close to Saimiri adds to the strength of this result. 


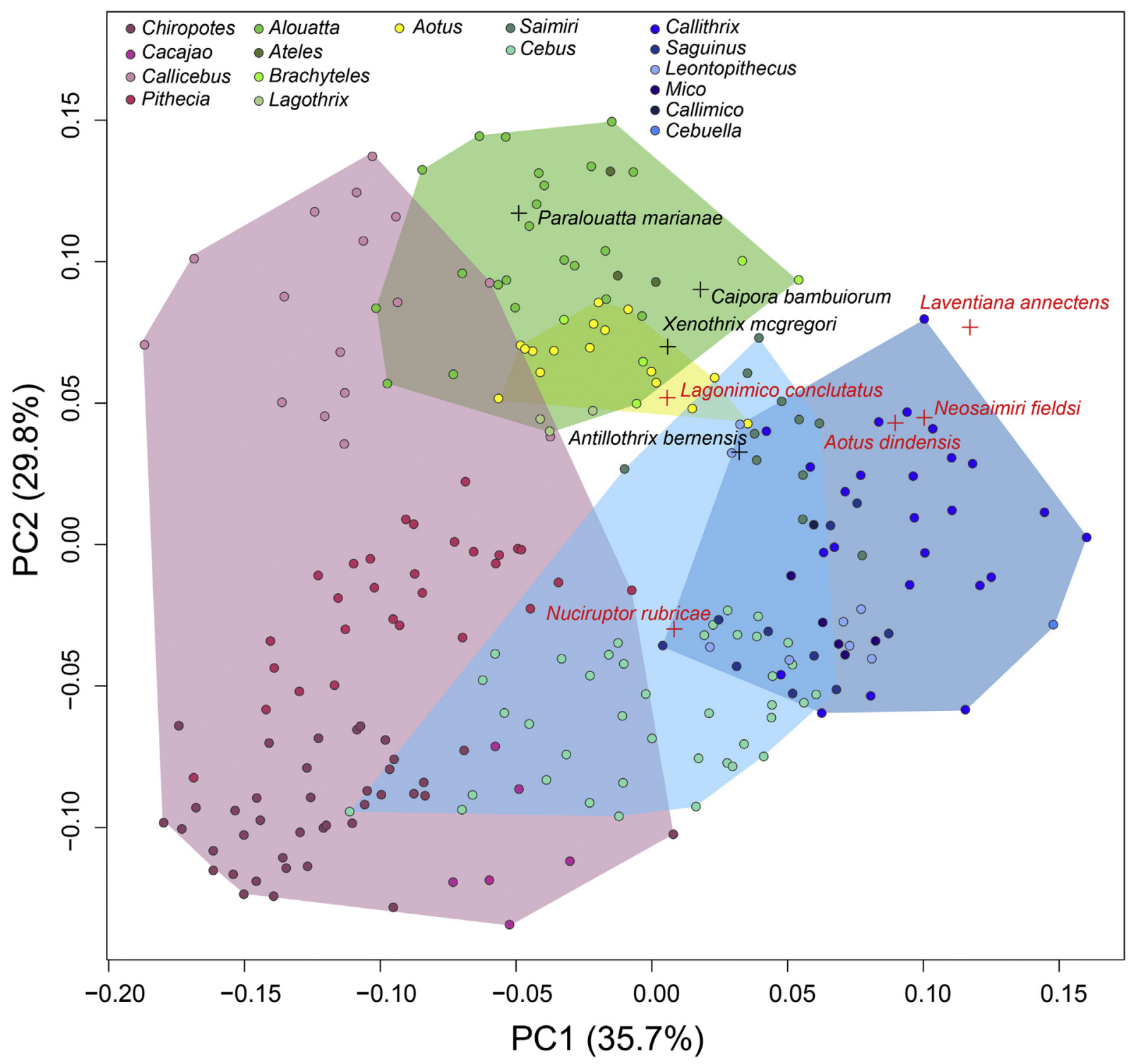

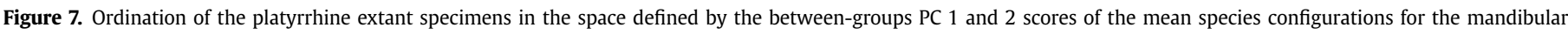

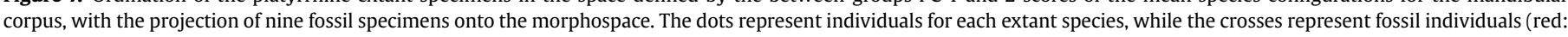

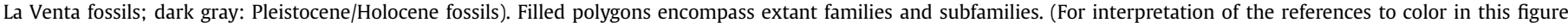
legend, the reader is referred to the web version of this article.)

On the other hand, the wide separation of Antillothrix from Callicebus is unexpected and does not align with other morphometric work, which showed the specimen as falling in the overlapping multidimensional space of Callicebus and Aotus (Rosenberger et al., 2013). Further investigation is required here. Similarly, A. dindensis falls relatively distant from the extant aotines. Nuciruptor appears to be situated in a novel shape space, although this may be interpreted as one anchored by pitheciines, with whom it is likely affiliated (Meldrum and Kay, 1997). The mandible of Nuciruptor, however, is more primitive than that of the modern pitheciines included here, so this result should not cause much debate. In general, fossils for which mandibular morphology is known seem to conform to the two patterns of platyrrhine mandibular morphology described above. One is a cebid pattern, and the other is an atelid-pitheciid pattern, which also encompasses the morphology of Aotus.

Recent studies using morphometrics of other systems that used extant platyrrhine species and phylogenetic comparative methods have demonstrated a strong relationship between phenotypic variation and species phylogeny (Perez et al., 2011; Aristide et al., 2015a, 2015b; Meloro et al., 2015). These findings add evidence to the global hypothesis of an early diversification followed by evolutionary stasis in platyrrhine evolution, a position advocated by Rosenberger (e.g., 1980, 1992), which was based on one of the first morphological trait analyses developed within the context of functional-ecological information. The broad cladistic outlines of that hypothesis have been widely accepted since it has been largely confirmed by molecular studies (Schneider and Rosenberger, 1996). Prior notions of platyrrhine evolution, i.e., by Hershkovitz (1977), were fraught with phylogenetic error, so the interaction - or correspondence - between phylogeny, morphology and adaptation was obscured. Until then, in primatology, it was rare for systematists and functional morphologists to see phylogeny and adaptation as intimately intertwined processes - two sides of the same coin as Szalay (2000) exhorted poignantly - where clues to revealing both facets reside in the same sets of characters, and both research domains benefit when characters are analyzed as if they are one. 
The phylogenetic signal analyses performed here on extant species allowed us to observe a strong relationship between phylogenetic structure and mandibular morphology. $K$ values for the main trends of morphological variation were near to 1 , as expected in characters evolving according to a Brownian motion evolutionary model (Losos, 2008). This is similar to the results of previous studies for complete mandible shape variation (Meloro et al., 2015). Additionally, the DTT plot, and mostly the one using evidence from the PC1 of extant species, shows high mandible variation during the early branching process, suggesting that morphological disparity of the mandible might have been partitioned among subclades early in the phylogenetic history of the crown platyrrhines (see Rosenberger, 1980, 1992). Therefore, we confirm for the mandibular corpus a strong phylogenetic structure that is also observed among platyrrhine species for other phenotypic traits and systems, such as body size, brain size and basicranial anatomy (Perez et al., 2011; Aristide et al., 2015a, 2015b).

The ordination present in the PCA of extant species and fossil specimens showed that during the early stages of platyrrhine diversification the mandible displays slightly larger amounts of variation, occupying a similar dispersion in morphospace and implying that mandible shapes similar to that of extant species might have been present at least since La Venta time (15-12 Ma). This result is concordant with the DTT-plot of PC1 and PC2 of extant species that suggests that diversification among the main clades in mandible shape occurred between 20 and $15 \mathrm{Ma}$ (Fig. 5b). This idea is also suggested by the nearness of fossil and extant species disparity values $\left(D_{\text {extant }}=0.026 ; D_{\text {extant }+ \text { fossils }}=0.029\right.$; $V_{\text {extant }}=0.0029 ; V_{\text {extant }+ \text { fossils }}=0.0031$ ). These analyses, plus the mapping and plotting of PC1 onto the phylogeny, may support the idea that there was an early differentiation of the varied mandibular morphologies that characterize each platyrrhine subclade in the present, followed by a marked stability in the evolution of these characters. Results like these may indicate that some lineages, such as Aotus and Callicebus, have retained elements of ancestral crown platyrrhine mandibular morphologies throughout their long history, as suggested by the Long Lineage Hypothesis (see Rosenberger, 2010).

Therefore, our analyses support the expectation that the morphological diversity of extant platyrrhine genera and species is similar to or slightly smaller than the diversity observed among the Miocene taxa ( 15-12 Ma ago). This result could suggest a long period of relative evolutionary stasis in mandible morphology after the early diversification of platyrrhines (Rosenberger, 1979, 1984; Rosenberger et al., 2009; Meloro et al., 2015; Aristide et al., 2015a). The early phase of modern crown platyrrhine evolution was probably characterized by a rapid diversification in morphological and ecological traits, driven by natural selection and ecological niche opportunity. The similarity in the variation among fossil and extant species also suggests that, after the initial phase, the rate of morphological diversification slowed down as niches were filled by diversifying ecomorphological clades. Moreover, it is possible that the platyrrhines may have gone through different processes of diversity loss in the past, thus reducing morphological disparity compared to that seen today. It is important to remark that even when fossil specimens analyzed in this study do not represent the earliest phase of platyrrhine diversification, their morphological resemblance to extant species may indicate at least 15 Ma of evolutionary stasis.

Summarizing, we show here that the conjoint study of extant and fossil species, in combination with the use of phylogenetic comparative methods, offers a deep quantifiable description of the diversification pattern through time and a refined understanding of platyrrhine evolutionary history. Our results suggest that the beginnings of platyrrhine diversification might be an example of the
Simpsonian ecospace model (Simpson, 1944), where similar or higher levels of morphological variation relative to that observed among the extant species are expected in the remote past, when the ecological niche space for a platyrrhine had not been exploited and the initial invasion could begin. Future advances in the studies of the morphological differentiation of platyrrhines would be enhanced with the recovery of additional and better-preserved fossil specimens and the employment of alternative phylogenetic comparative modeling approaches. This would increase the sample size, the analyzed morphological traits and the accessible time range, and it would allow us to test different evolutionary scenarios for platyrrhine diversification.

\section{Acknowledgments}

We thank D. Flores (Museo Argentino de Ciencias Naturales "Bernardino Rivadavia", Argentina) and D. Verzi (Museo de La Plata, Argentina) for granting access to the platyrrhine skeletal collections under their care. Raquel Lamela-Lopez photographed some of the mandible used in this study. We also thank three anonymous reviewers who contributed greatly to improving the manuscript. This research was supported by a grant from FONCYT (PICT-2014-1810; 2015-2018), CONICET (PIP 112-200901-00132; 2014-2016) and UNLP (PI- N787 2015-2018).

\section{Supplementary Online Material}

Supplementary online material related to this article can be found at http://dx.doi.org/10.1016/j.jhevol.2017.08.008.

\section{References}

Adams, D.C., 2014. Quantifying and comparing phylogenetic evolutionary rates for shape and other high-dimensional phenotypic data. Syst. Biol. 63, 166-177.

Adams, D.C., Otárola-Castillo, E., 2013. geomorph: an R package for the collection and analysis of geometric morphometric shape data. Methods Ecol. Evol. 4, 393-399.

Alvarez, A., Perez, S.I., 2012. Two- versus three-dimensional morphometric approaches in macroevolution: insight from the mandible of caviomorph rodents. J. Evol. Biol. 40, 150-157.

Alvarez, A., Perez, S.I., Verzi, D.H., 2011. Early evolutionary differentiation of morphological variation in the mandible of South American caviomorph rodents (Rodentia, Caviomorpha). J. Evol. Biol. 24, 2687-2695.

Anapol, F., Lee, S., 1994. Morphological adaptation to diet in platyrrhine primates. Am. J. Phys. Evol. 94, 239-261.

Aristide, L., Rosenberger, A.L., Tejedor, M.F., Perez, S.I., 2015a. Modeling lineage and phenotypic diversification in the New World monkey (Platyrrhini, Primates) radiation. Mol. Phylogenet. Evol. 82, 375-385.

Aristide, L., dos Reis, S.F., Machado, A.C., Lima, I., Lopes, R.T., Perez, S.I., 2015b. Encephalization and diversification of the cranial base in platyrrhine primates. J. Hum. Evol. 81, 29-40.

Atchley, W.R., Hall, B.K., 1991. A model for development and evolution of complex morphological structures. Biol. Rev. 66, 101-157.

Benton, M.J., 2015. Exploring macroevolution using modern and fossil data. Proc. R. Soc. Lond. B. 282, 20150569.

Blomberg, S.P., Garland Jr., T., Ives, A.R., 2003. Testing for phylogenetic signal in comparative data: behavioral traits are more labile. Evolution 57, 717-745.

Bond, M., Tejedor, M.F., Campbell Jr., K.E., Chornogubsky, L., Novo, N., Goin, F., 2015. Eocene primates of South America and the African origins of New World monkeys. Nature 520, 538-541.

Cartelle, C., Hartwig, W.C., 1996. A new extinct primate among the Pleistocene megafauna of Bahia, Brazil. Proc. Natl. Acad. Sci. 93, 6405-6409.

Cheverud, J.M., Ehrich, T.H., Vaughn, T.T., Koreishi, S.F., Linsey, R.B., Pletscher, L.S., 2004. Pleiotropic effects on mandibular morphology II: differential epistasis and genetic variation in morphological integration. J. Exp. Zool. B Mol. Dev. Evol. 302, 424-435.

Cooke, S.B., Rosenberger, A.L., Turvey, S., 2011. An extinct monkey from Haiti and the origins of the Greater Antillean primates. Proc. Natl. Acad. Sci. 108, 2699-2704.

Delson, E., Rosenberger, A.L., 1984. Are there any anthropoid primate "living fossils"? In: Eldredge, N., Stanley, S. (Eds.), Casebook on Living Fossils. Fischer Publishers, New York, pp. 50-61.

Felsenstein, J., 1985. Phylogenies and the comparative method. Am. Nat. 125, 1-15.

Fleagle, J.G., 2013. Primate Adaptation and Evolution, 3rd ed. Academic Press, San Diego. 
Fleagle, J.G., Tejedor, M.F., 2002. Early platyrrhines of southern South America. In: Hartwig, W.C. (Ed.), The Primate Fossil Record. Cambridge University Press, Cambridge, pp. 161-173.

Ford, S.M., Davis, L.C., 1992. Systematics and body size: implications for feeding adaptations in New World monkeys. Am. J. Phys. Anthropol. 88, 415-468.

Foote, M., 1993. Contributions of individual taxa to overall morphological disparity. Paleobiology 19, 403-419.

Gavrilets, S., Losos, J.B., 2009. Adaptive radiation: contrasting theory with data. Science 323, 732-737.

Gower, J.C., 1971. A general coefficient of similarity and some of its properties. Biometrics 27, 857-871.

Gunz, P., Mitteroecker, P., 2013. Semilandmarks: a method for quantifying curves and surfaces. Hystrix 24, 103-109.

Halenar, L.B., Rosenberger, A.L., 2013. A closer look at the "Protopithecus" fossil assemblages: new genus and species from Bahia, Brazil. J. Hum. Evol. 65, $374-390$.

Harmon, L.J., Schulte II, J.A., Larson, A., Losos, J.B., 2003. Tempo and mode of evolutionary radiation in Iguanian lizards. Science 301, 961-964.

Harmon, L.J., Weir, J.T., Brock, C.D., Glor, R.E., Challenger, W., 2008. GEIGER: investigating evolutionary radiations. Bioinformatics 24, 129-131.

Hartwig, W.C., Meldrum, J.D., 2002. Miocene platyrrhines of the northern neotropics. In: Hartwig, W.C. (Ed.), The Primate Fossil Record. Cambridge University Press, New York, pp. 175-188.

Hershkovitz, P., 1974. A new genus of late Oligocene monkey (Cebidae, Platyrrhini) with notes on postorbital closure and platyrrhine evolution. Folia Primatol. 21(1), 1-35.

Hershkovitz, P., 1977. Living New World Monkeys (Platyrrhini), vol. 1. University of Chicago Press Books, Chicago.

Hylander, W.L., 1979. The functional significance of primate mandibular form. J. Morphol. 160(2), 223-229.

Hylander, W.L., 1985. Mandibular function and biomechanical stress and scaling. Am. Zool. 25(2), 315-330.

Jackson, D.A., 1995. PROTEST: A PROcrustean Randomization TEST of community environment concordance. Ecoscience 2, 297-303.

Kay, R.F., 1990. The phyletic relationships of extant and fossil Pitheciinae. J. Hum. Evol. 19, 175-208.

Kay, R.F., 1994. "Giant" tamarin from the Miocene of Colombia. Am. J. Phys. Anthropol. 95, 333-353.

Kay, R.F., 2015. Biogeography in deep time - what do phylogenetics, geology, and paleoclimate tell us about early platyrrhine evolution? Mol. Phylogenet. Evol. $82,358-374$.

Kay, R.F., Fleagle, J.G., Mitchell, T.R.T., Colbert, M., Brown, T., Powers, D.W., 2008. The anatomy of Dolichocebus gaimanensis, a stem platyrrhine monkey from Argentina. J. Hum. Evol. 54, 323-382.

Kembel, S.W., Cowan, P.D., Helmus, M.R., Cornwell, W.K., Morlon, H., Ackerly, D.D., Blomberg, S.P., Webb, C.O., 2010. Picante: R tools for integrating phylogenies and ecology. Bioinformatics 26, 1463-1464.

Kinzey, W.G., 1997. New World Primates: Ecology, Evolution, and Behavior. Aldine de Gruyter, New York.

Lemey, M., Salemi, M., Vandamme, A.M., 2009. The Phylogenetic Handbook: A Practical Approach to Phylogenetic Analysis and Hypothesis Testing. Cambridge University Press, Cambridge.

Losos, J.B., 2008. Phylogenetic niche conservatism, phylogenetic signal and the relationship between phylogenetic relatedness and ecological similarity among species. Ecol. Lett. 11, 995-1007.

Losos, J.B., 2011. Seeing the forest for the trees: the limitations of phylogenies in comparative biology. Am. Nat. 177, 709-727.

Losos, J.B., Mahler, D.L., 2010. Adaptive radiation: the interaction of ecological opportunity, adaptation, and speciation. In: Bell, M.A., Futuyma, D.J., Eanes, W.F., Levinton, J.S. (Eds.), Evolution Since Darwin: The First 150 Years. Sinauer Associates, Sunderland, pp. 381-420.

MacPhee, R.D.E., Fleagle, J.G., 1991. Postcranial remains of Xenothrix mcgregori (Primates, Xenotrichidae) and other late Quaternary mammals from Long Mile Cave, Jamaica. Bull. Am. Mus. Nat. Hist. 206, 287-321.

Macphee, R.D.E., Horovitz, I., 2008. Extinct Quaternary platyrrhines of the Greater Antilles and Brazil. In: Hartwig, W.C. (Ed.), The Primate Fossil Record. Cambridge University Press, New York, pp. 189-200.

Mahler, D.L., Revell, L.J., Glor, R.E., Losos, J.B., 2010. Ecological opportunity and the rate of morphological evolution in the diversification of Greater Antillean anoles. Evolution 64, 2731-2745.

Martins, E.P., Hansen, T.F., 1997. Phylogenies and the comparative method: a general approach to incorporating phylogenetic information into the analysis of interspecific data. Am. Nat. 149, 646-667.

Meldrum, D.J., Kay, R.F., 1997. Nuciruptor rubricae, a new pitheciin seed predator from the Miocene of Colombia. Am. J. Phys. Anthropol. 102, 402-427.

Meloro, C., Cáceres, N.C., Carotenuto, F., Sponchiado, J., Melo, G.L., Passaro, F., Raia, P., 2015. Chewing on the trees: constraints and adaptation in the evolution of the primate mandible. Evolution 69, 1690-1700.

Mitteroecker, P., Bookstein, F., 2011. Linear discrimination, ordination, and the visualization of selection gradients in modern morphometrics. Evol. Biol. 38, 100-114.

Mitteroecker, P., Gunz, P., 2009. Advances in geometric morphometrics. Evol. Biol. 36, 235-247.

Neige, P., 2003. Spatial patterns of disparity and diversity of the recent cuttlefishes (Cephalopoda) across the Old World. J. Biogeogr. 30, 1125-1137.
Oksanen, J., Blanchet, F.G., Kindt, R., Legendre, P., Minchin, P.R., O'Hara, R.B., Simpson, G.L., Solymos, P., Stevens, M.H.H., Wagner, H., 2014. Vegan: Community Ecology Package. R Package Version 2.2-0. http://CRAN.Rproject.org/ package=vegan.

Opazo, J.C., Wildman, D.E., Prychitko, T., Johnson, R.M., Goodman, M., 2006. Phylogenetic relationships and divergence times among New World monkeys (Platyrrhini, Primates). Mol. Phylogenet. Evol. 40, 274-280.

Orme, D., 2013. The caper package: comparative analysis of phylogenetics and evolution in R. R Package Version 0.5, 2. https://cran.r-project.org/web/ packages/caper/index.html.

Perelman, P., Johnson, W.E., Roos, C., Seuánez, H.N., Horvath, J.E., Moreira, M.A.M., Kessing, B., Pontius, J., Roelke, M., Rumpler, Y., Schneider, M.P.C., Silva, A., O'Brien, S.J., Pecon-Slattery, J., 2011. A molecular phylogeny of living primates. PloS Genet. 7, e1001342.

Peres-Neto, P., Jackson, D.A., 2001. How well do multivariate data sets match? The advantages of a Procrustean superimposition approach over the Mantel test. Oecologia 129, 169-178.

Perez, S.I., Bernal, V., Gonzalez, P.N., 2006. Differences between sliding semilandmark methods in geometric morphometrics, with an application to human craniofacial and dental variation. J. Anat. 208, 769-784.

Perez, S.I., Diniz-Filho, J.A.F., Rohlf, F.J., dos Reis, S.F., 2009. Ecological and evolutionary factors in the morphological diversification of South American spiny rats. Biol. J. Linn. Soc. 98, 646-660.

Perez, S.I., Klaczko, J., Rocatti, G., dos Reis, S.F., 2011. Patterns of cranial shape diversification during the phylogenetic branching process of New World monkeys (Primates: Platyrrhini). J. Evol. Biol. 24, 1826-1835.

Perez, S.I., Tejedor, M.F., Nelson, N.M., Aristide, L., 2013. Divergence times and the evolutionary radiation of New World monkeys (Platyrrhini, Primates): an analysis of fossil and molecular data. PLOS ONE 8, e68029.

Ravosa, M.J., 1996. Jaw morphology and function in living and fossil Old World monkeys. Int. J. Primatol. 17(6), 909-932.

R Development Core Team, 2015. R: a language and environment for statistical computing. R Foundation for Statistical Computing, Vienna.

Revell, L.J., Mahler, D.L., Peres-Neto, P.R., Redelings, B.D., 2012. A new phylogenetic method for identifying exceptional phenotypic diversification. Evolution 66, 135-146.

Rohlf, F.J., 2001. Comparative methods for the analysis of continuous variables: geometric interpretations. Evolution 55, 2143-2160.

Rohlf, F.J., 2015. The tps series of software. Hystrix 26, 9-12.

Rosenberger, A.L., 1977. Xenothrix and ceboid phylogeny. J. Hum. Evol. 6, 461-481.

Rosenberger, A.L., 1979. Cranial anatomy and implications of Dolichocebus, a late Oligocene ceboid primate. Nature 279, 416-418.

Rosenberger, A.L., 1980. Gradistic views and adaptive radiation of platyrrhine primates. Z. Morphol. Anthropol. 71, 157-163.

Rosenberger, A.L., 1984. Fossil New World monkeys dispute the molecular clock. J. Hum. Evol. 13, 737-742.

Rosenberger, A.L., 1992. Evolution of feeding niches in New World monkeys. Am. J. Phys. Anthropol. 88, 525-562.

Rosenberger, A.L., 2002. Platyrrhine paleontology and systematics: the paradigm shifts. In: Hartwig, W.C. (Ed.), The Primate Fossil Record. Cambridge University Press, New York, pp. 151-160.

Rosenberger, A.L., 2010. Platyrrhines, PAUP, parallelism, and the long lineage hypothesis: a reply to Kay et al. (2008). J. Hum. Evol. 59, 214-217.

Rosenberger, A.L., Hartwig, W.C., Wolff, R.G., 1991. Szalatavus attricuspis, an early platyrrhine primate. Folia Primatol. 56(4), 225-233.

Rosenberger, A.L., Tejedor, M.F., 2013. The misbegotten: long lineages, long branches and the interrelationships of Aotus, Callicebus and the saki-uakaris. In: Barnett, A.L., Veiga, S., Ferrari, S., Norconk, M.N. (Eds.), Evolutionary Biology and Conservation of Titis, Sakis and Uacaris. Cambridge University Press, Cambridge, pp. 13-22.

Rosenberger, A.L., Tejedor, M.F., Cooke, S.B., Pekar, S., 2009. Platyrrhine ecophylogenetics in space and time. In: Garber, P.A., Estrada, A., Bicca-Marques, J.C. Heymann, E.W., Strier, K.B. (Eds.), South American Primates: Comparative Perspectives in the Study of Behavior, Ecology and Conservation. Springer, New York, pp. 69-113.

Rosenberger, A.L., Halenar, L., Cooke, S.B., Hartwig, W.C., 2012. Morphology and evolution of the spider monkey, genus Ateles. In: Campbell, C.J. (Ed.), Spider Monkeys: Behaviour, Ecology and Evolution of the Genus Ateles. Cambridge University Press, New York, pp. 19-49.

Rosenberger, A.L., Klukkert, Z.S., Cooke, S.B., Rímoli, R., 2013. Rethinking Antillothrix: the mandible and its implications. Am. J. Primatol. 75, 825-836.

Ross, C.F., Iriarte-Diaz, J., Nunn, C.L., 2012. Innovative approaches to the relationship between diet and mandibular morphology in primates. Int. J. Primatol. 33(3), 632-660.

Schneider, H., Rosenberger, A.L., 1996. Molecules, morphology and platyrrhine systematics. In: Norconk, M.A., Rosenberger, A.L., Garber, P.A. (Eds.), Adaptive Radiations of Neotropical Primates. Plenum Press, New York, pp. 3-19.

Setoguchi, T., Rosenberger, A.L., 1987. A fossil owl monkey from La Venta, Colombia. Nature 326, 692-694.

Simpson, G.G., 1944. Tempo and Mode in Evolution. Columbia University Press, New York.

Szalay, F.S., 2000. Function and adaptation in paleontology and phylogenetics: why do we omit Darwin? Palaeontol. Electron. 3, 1-25.

Takai, M., 1994. New specimens of Neosaimiri fieldsi from La Venta, Colombia: a middle Miocene ancestor of the living squirrel monkeys. J. Hum. Evol. 27, 329-360. 
Tejedor, M.F., Rosenberger, A.L., 2008. A neotype for Homunculus patagonicus, Ameghino, 1891, and a new interpretation of the taxon. PaleoAnthropology 2008, 68-82.

Terborgh, J., 1983. Five New World Primates: A Study in Comparative Ecology. Princeton University Press, New Jersey.

Terhune, C.E., Cooke, S.B., Otárola-Castillo, E., 2015. Form and function in the platyrrhine skull: a three-dimensional analysis of dental and TMJ morphology. Anat. Rec. 298, 29-47.

Winchester, J.M., Boyer, D.M., St. Clair, E.M., Gosselin-Ildari, A.D., Cooke, S.B., Ledogar, J.A., 2014. Dental topography of platyrrhines and prosimians: convergence and contrasts. Am. J. Phys. Anthropol. 153, 29-44.

Wiens, J.J., 2009. Estimating rates and patterns of morphological evolution from phylogenies: lessons in limb lability from Australian Lerista lizards. J. Biol. 8, 19.
Wilson, D.E., Reeder, D.M., 2005. Mammal Species of the World. A Taxonomic and Geographic Reference, 3rd ed. John Hopkins University Press, Baltimore, MD.

Wolff, R.G., 1984. New specimens of the primate Branisella boliviana from the early Oligocene of Salla, Bolivia. J. Vertebr. Paleontol. 4(4), 570-574.

Yang, Z., Rannala, B., 2012. Molecular phylogenetics: principles and practice. Nat. Rev. Genet. 13, 303-314.

Youlatos, D., Meldrum, J., 2011. Locomotor diversification in New World monkeys: running, climbing, or clawing along evolutionary branches. Anat. Rec. 294, 1991-2012.

Zelditch, M.L., Swiderski, D.L., Sheets, H.D., Fink, W.L., 2004. Geometric Morphometrics for Biologists: A Primer. Elsevier Academic Press, London. 